\title{
High Potential Employees - Building it Right
}

\author{
Dr Santhosh Koyadan Veettil \\ "At the end of the day, the company with the best team, the best people will win in the long run." (GE)
}

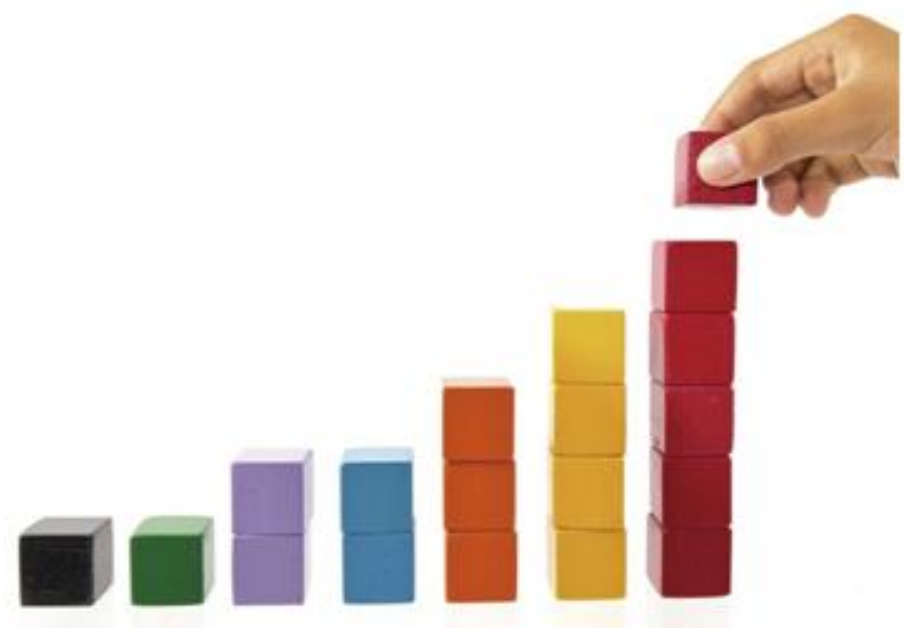

In today's international market place, the widely accepted grim reality remains as if it is going to stay. Competition for the best talents is at its peak. Even in a trailing economy where the supply far exceeds the demand, the crunch is felt for the 'best fit' or 'top talents.

Over the next two decades, 10,000 baby boomers will turn 65 everyday, leaving a cavernous hole in the talent market. As the economy continues its slow path to recovery,34\% of companies globally report having trouble filling vacancies due to talent shortages. This statistic isup from $30 \%$ in 2009 , indicating that as the economy improves, the war for talent will become even morefierce. With the convergence of an amplified focus on growth and a graying workforce, the strain on theavailable pool of talent will be immense. This crisis is global in scope and currently affects employers all over the world. (White Paper, AON Hewitt, January 2013)

The shortage of skilled talent will be felt more and more in the years to come. Although the supply seemingly gives a cushion, in reality employers are battling with the mismatch between available candidates and the needed technical expertise.We are all aware that the oil and gas industry is going through the rough tide of price war. Nevertheless the need for skilled engineers are on the rise. Big players will continue to expand their production as well the small ones. Then the fight for talent will be even more worse.

Progressive leaders understand that a solid talent bench is quite literally thelifeline to their future success. The factors cited above and more have created an urgency for organisations to focus on identifying, developing and retaining the best talent. Thus, developing high potentials is a crucial component of a company'sbusiness strategy, as it directly feeds or depletes the collection of talent capable of filling impendingsenior leadership vacancies. The question here then is 'How many of those organisations out there are focusing on building the right people to be their next generation leaders? How many of those line managers are investing their time in identifying their High Potentials and help them in their career?

\section{Career Development Discussions - Need of the hour}

Individuals working for organisations have a pressing need to manage their own careers effectively. They need to do this to progress within their current employing organisation towards more interesting, more responsible and more highly rewarded work. This is the conventional, and still often relevant, meaning of 'career'. But individuals also need to manage their own careers to make sideway moves as well. Organisations who manages these expectations effectively and create an engaging workforce will stands out from the rest.

The established annual performance appraisal process can be a good place to raise career issues but not often to explore or resolve them. A separate discussion on another occasion will usually be needed. Separate development reviews and personal development plans (PDPs) may allow more time but still may not enable genuine exploration of career development issues. More frequent one-to-one meetings between boss and subordinate may be a better forum in which to raise and discuss career issues as they arise. If the organisation plans for people's careers, this should be transparent to the individual. Thus a career development discussion 
becomes a crucial activity which supports the talent management process. Most organizations adopt career development programs in response to pragmatic human resource concerns and because they believe it will help ensure a continued supply of qualified, talented personnel.

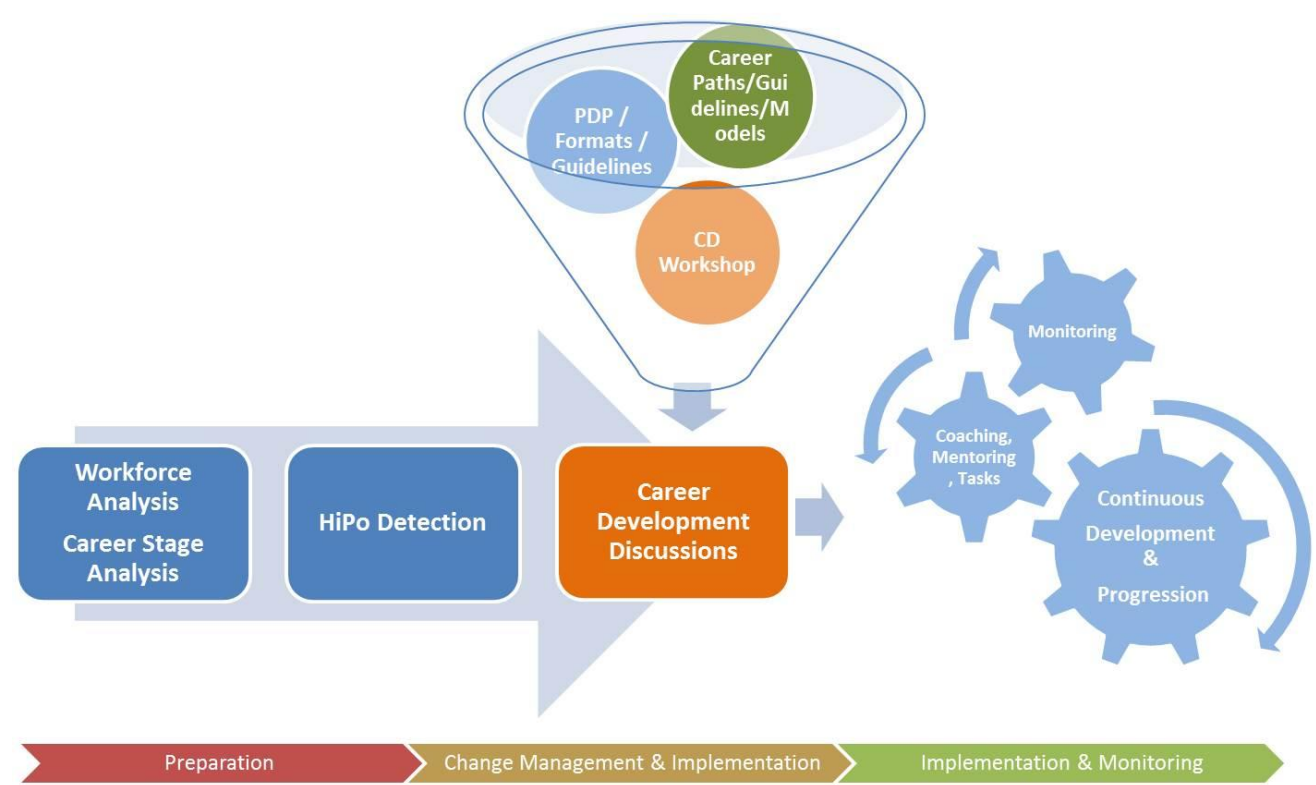

A critical engagement piece most often overlooked by organisations is the 'Career Discussion' piece (as shown in the Fig above) which if carried out effectively can yield great results in terms of employee motivation, engagement and retention. Although career discussions might happen between a manager and his/her employee which may not be done intentionally by both parties, a guidance to an effective discussion will help in bringing out tangible results for the employee as well as for the organisation. The change management piece shown above is crucial since it involves engagement of managers and supervisors in this process. An understanding of 'how to read and use' the various tools of talent management (PDP-Personal Development Plans, Various Formats, Career Paths, Talent Tools), what to say and what not to say, how to manage expectations and handle difficult employees - all these will enable a supervisor/manager in making effective career discussions.

Responsibility for career management largely rests in a partnership between the individual and their supervisors, although supervisors receive little training to deliver effective career support which in most cases is the sole reason why they hesitate (or rather 'afraid') to have a frank and free discussion with their subordinates.A conscious effort on the part of organisations to empower their line managers to do effective career conversations for sure will pay dividend in the long run as it creates valuable High Potential and High Performing employees for the future.

End - 